\title{
Análisis jurídico sobre la evolución del delito de usura en la Legislación Ecuatoriana
}

\section{Legal analysis on the evolution of the crime of usury in Ecuadorian Law}

\author{
Cesar Gabino Cando-Vinces \\ ud.cesargcv33@uniandes.edu.ec \\ Universidad Regional Autónoma de Los Andes, Quevedo \\ Ecuador \\ https://orcid.org/0000-0001-6942-5726 \\ Julio César de Jesús Arrias-Añez \\ uq.julioarrias@uniandes.edu.ec \\ Universidad Regional Autónoma de Los Andes, Quevedo \\ Ecuador \\ https://orcid.org/0000-0001-5259-9359 \\ Cesar Elias Paucar-Paucar \\ uq.cesarpaucar@uniandes.edu.ec \\ Universidad Regional Autónoma de Los Andes, Quevedo \\ Ecuador \\ https://orcid.org/0000-0003-2624-0427
}

Recibido: 15 de septiembre de 2020

Revisado: 20 de octubre de 2020

Aprobado: 04 de diciembre de 2020

Publicado: 11 de diciembre de 2020 


\title{
RESUMEN
}

La investigación tiene como objetivo realizar un análisis jurídico sobre la evolución del delito de usura en la legislación ecuatoriana con el objeto de medir la eficiencia y eficacia de la normativa vigente en la materia de delitos que afectan el patrimonio. Desde el ámbito metodológico se desarrolló bajo el enfoque analítico - sintético y a nivel descriptivo-documental desde un diseño bibliográfico; analizándose la información recopilada a través de la técnica de análisis de contenido, agrupándose aspectos teoréticos sobre el tema de la usura en el derecho del Ecuador. Se concluye que la usura representa un tipo penal que atenta contra la capacidad económica y financiera de las víctimas al ocasionar una disminución de su capital como consecuencia de estipularse un interés mayor al previsto en la ley, atentando contra el sistema financiero en detrimento de la política monetaria nacional, socavando el principio del comercio justo.

Descriptores: Financiación; derechos civiles; derecho penal. (Palabras tomadas del Tesauro UNESCO).

\begin{abstract}
The objective of the research is to carry out a legal analysis on the evolution of the crime of usury in Ecuadorian legislation in order to measure the efficiency and effectiveness of current regulations on crimes that affect property. From the methodological field it was developed under the analytical-synthetic approach and at a descriptive-documentary level from a bibliographic design; analyzing the information collected through the content analysis technique, grouping theoretical aspects on the subject of usury in the law of Ecuador. It is concluded that usury represents a criminal type that threatens the economic and financial capacity of the victims by causing a decrease in their capital as a consequence of stipulating an interest greater than that provided by law, attacking the financial system to the detriment of politics monetary policy, undermining the principle of fair trade.
\end{abstract}

Descriptors: Financing; civil and political rights; criminal law. (Words taken from the UNESCO Thesaurus). 


\section{INTRODUCCIÓN}

La presente investigación versa sobre el análisis jurídico de la evolución que ha tenido el delito de Usura dentro de la legislación ecuatoriana, es un tema importante por cuanto se examina el proceso de prestación de dineros a grandes intereses que exceden el porcentaje permitido por el ordenamiento jurídico, coyuntura real y objetiva que representa una problemática actual en la sociedad, es por esto que en el presente trabajo investigativo se analizó la historia, evolución y aplicación de la usura a nivel general y por ende en la legislación actual que prevalece en el Ecuador.

A nivel jerárquico, la Constitución de la República del Ecuador de 2008 (Asamblea Nacional, 2008), es la norma suprema y de rango máximo vigente dentro del ordenamiento jurídico junto a los tratados internacionales en materia de derechos humanos, las demás; leyes orgánicas, leyes ordinarias, leyes especiales, reglamentos, resoluciones y tratados internacionales, deberán estar enmarcadas a la Carta Magna, respetando su integridad. A nivel legal en el país, se deberá respetar el organigrama de jerarquía, existente para participar del debido proceso, esta mención se toma como antecedente al tema al tratar en el presente artículo el tipo penal de Usura. (Toral-Aguilar, 2015).

En el Ecuador existen una serie de normas legales que han sido aplicadas por parte de las autoridades, en varias ocasiones en sentido contrario a lo que prevé el ordenamiento jurídico, en el contexto ecuatoriano los mandatos constitucionales no tienen un fiel cumplimiento y esta coyuntura genera muchos de esos problemas ocasionados por la falta o indebida aplicación de lo que la ley establece y por ende esto representa el detrimento de la seguridad jurídica.

El delito de la usura, genera una serie de problemas a la estabilidad financiera y económica de sus víctimas, dicho tipo penal se perpetra a través de una rúbrica de documento y letras de cambio en blanco con firmas de aval; en perjuicio de débiles jurídicos que caen en un estado de indefensión, en virtud del dinamismo doloso que emerge de una sociedad que se va transformando y cada vez se vuelve más complicada, el avance de nuevas tendencias, la ciencia, y la tecnología que han dado lugar a que se produzcan una serie de complicaciones imaginables, por ello, uno de 
los entes rectores de manejo de las leyes en Ecuador, la Asamblea Nacional, por medio de los asambleístas con una visión futurista y acorde a las situaciones que se presentan diariamente deben regular estos hechos a través de la sanción de normas jurídicas.

Las leyes han regulado la conducta del ser humano y de la sociedad misma, la tipificación de los delitos y su sanción han sido motivo de diferentes fallos contradictorios, en ciertas ocasiones han sido sancionadas con apego a la ley, y en muchas otras han generado impunidad por una errónea ejecución de la sana crítica en la valoración de las pruebas al no aplicar de manera idónea los conocimientos jurídicos, las reglas de la lógica y las máximas de experiencia los órganos subjetivos encargados de administrar justicia, generando negligencia e inobservancia de los mandatos jurídicos, sobre todo cuando la usura, se extrapola a escenarios sociales como la economía informal o de pequeñas empresas, las cuales suelen ser alteradas por préstamos en usura, causando no solo un daño patrimonial directo al empresario, sino, a la colectividad, por cuanto, se hace común un delito que daña la economía nacional (Solórzano-Aveiga, 2018).

Por lo tanto, el tema de usura afecta considerablemente la rentabilidad de la economía nacional, posibilitando la generación de ramificar el delito, especialmente relacionado a evasión de impuestos (Ochoa-González, et al., 2016), es así la importancia del tema sobre el análisis jurídico de la evolución delito de usura en la legislación ecuatoriana partiendo de instrumentos jurídicos importantes derogados y vigentes como fue el Código Penal derogado en el año 2014 por la sanción del Código Orgánico Integral Penal vigente desde el año 2014, es un contenido por demás significativo, debido a que, de esta manera se estaría protegiendo de un modo adecuado y eficaz la seguridad jurídica de las personas que son, fueron y pudieren ser perjudicados con este delito, esto conlleva además a un grado característico propio para la realización y la elaboración de un artículo científico y de investigación, siendo que además, en el caso de que la usura se desarrolle de patrón a empleados, debe velarse por la igualdad de condiciones, especialmente de la mujer, discapacitados, personas en 
condiciones de vulnerabilidad social, con la finalidad de evitar esta acción en ámbitos laborales (Masabanda-Analuiza, et al., 2019).

Asimismo, brinda un nuevo punto de vista de las nuevas formas de llevar las leyes que se tienen dentro del país, por lo que es necesario realizar un estudio que informen a los profesionales del derecho y estudiantes acerca de las formas de proceder al momento de presentación de las pruebas, además de ciertos trámites penales a realizarse por cuanto la comisión de este tipo penal se ha convertido en un flagelo que atenta contra el patrimonio personal de las víctimas, aunque la usura no puede considerarse una tipología novedosa, lo que hace necesaria comprender su dimensión para establecer parámetros jurídicos de hacer efectiva la penalidad contra el mismo (Barroso-González, 2015). En razón de lo expuesto, se plantea el siguiente objetivo de investigación:

Realizar un análisis jurídico sobre la evolución del delito de usura en la legislación ecuatoriana con el objeto de medir la eficiencia y eficacia de la normativa vigente en la materia de delitos que afectan el patrimonio.

\section{MÉTODO}

Se desarrolló la investigación desde la concepción del método analítico - sintético, centralizándose en el análisis sobre la usura como objeto investigativo, así se procesó un recorrido interpretativo de las partes que lo conforman, siendo estas provistas por textos enfocados desde el ámbito jurídico - académico, constituyéndose esta, en la muestra poblacional, de ese modo, se propuso una síntesis teórica desde la reflexión argumentativa de los investigadores, cumpliéndose con las premisas epistémicas de este método en concordancia con lo planteado por (Lopera-Echavarría, et al., 2010), para estudios jurídicos.

De ese modo, la investigación desde el ámbito metodológico, fue de tipo descriptiva documental con diseño bibliográfico, analizándose la información recopilada a través de la técnica de análisis de contenido, agrupándose aspectos teoréticos sobre el tema de la usura en el derecho del Ecuador. 


\section{RESULTADOS}

Se realizó un análisis crítico para extraer los aspectos positivos y negativos que puedan servir en el esclarecimiento y antecedentes de la problemática, los criterios y doctrinas, retrospectivamente expresadas en el tiempo en relación a la evolución del delito de usura en la legislación ecuatoriana.

La usura se ha mantenido a lo largo de los tiempos a pesar de la intención de limitarla ya sea por la religión o la ley. En base al diagnóstico actual sobre la evolución del delito de usura en la legislación ecuatoriana, se pudo detectar que su tipificación se adapta a la dimensión real de este tipo penal en armonía al contexto internacional, llenando los vacíos legales que presentaba el código penal derogado en el año 2014 y que permitía interpretaciones erróneas a favor de los usureros, en virtud de la errada apreciación de las pruebas por parte de los juzgadores.

Esta conducta lesiva se encuentra contemplada en el Código Orgánico Integral penal que data del año 2014, el mismo se encuentra descrito en la Sección Octava relativa a los delitos económicos, siendo tipificado en el artículo 309 de la siguiente manera:

La persona que otorgue un préstamo directa o indirectamente y estipule un interés mayor que el permitido por ley, será sancionada con pena privativa de libertad de cinco a siete años. Cuando el perjuicio se extienda a más de cinco personas, será sancionada con pena privativa de libertad de siete a diez años. La persona que simule la existencia de un negocio jurídico y oculte un préstamo usurario, será sancionada con pena privativa de libertad de cinco a siete años. En estos casos se ordenará la devolución a la víctima de lo hipotecado o prendado y la restitución de todo lo pagado de manera ilegal (Asamblea Nacional de la República del Ecuador, 2014).

Este supuesto de hecho descrito como conducta prohibida en el artículo previamente citado, tiene su base en los postulados previstos en el artículo. 290 literal 4 de la Constitución de la República del Ecuador del año 2008, que contempla: "Los convenios de renegociación no contendrán, de forma tácita o expresa, ninguna forma de anatocismo o usura", en concordancia con lo previsto en el Artículo. 308 de la misma Constitución de Montecristi del 2008, que consagra el sistema financiero en el cual ordena: "El Estado fomentará el acceso a los servicios financieros y a la democratización del crédito. Se prohíben las prácticas colusorias, el anatocismo y la 
usura". En este orden de ideas, las premisas descritas van en armonía con las disposiciones previstas en el artículo 335 íbidem y en el cual establece los intercambios económicos y el comercio justo, al sostener lo siguiente:

El Estado regulará, controlará e intervendrá, cuando sea necesario, en los intercambios y transacciones económicas; y sancionará la explotación, usura, acaparamiento, simulación, intermediación especulativa de los bienes y servicios, así como toda forma de perjuicio a los derechos económicos y a los bienes públicos y colectivos. El Estado definirá una política de precios orientada a proteger la producción nacional, establecerá los mecanismos de sanción para evitar cualquier práctica de monopolio y oligopolio privados, o de abuso de posición de dominio en el mercado y otras prácticas de competencia desleal.

En este escenario, la usura ha sido descrita a través de la doctrina económica y jurídica por grandes tratadistas, a continuación, el investigador trae a colación algunas definiciones sobre el fenómeno de estudio para entender como ha sido su evolución a través de la historia:

La palabra usura proviene de usum, conforme a una significación que toman de Cicerón12 pero que, incluso en los propios textos del romano, puede interpretarse como mero uso, aunque también como aumento (Lértora-Mendoza, 2013), por otro lado, el concepto de usura presenta algunas variantes conforme a dos criterios expositivos, el primero, la usura se define de modo general y previo a la consideración de su calificación moral; y el segundo, la usura es definida como un tipo especial de contrato moralmente ilícito (Toral-Aguilar, 2015).

En este segundo caso, solo algún tipo dentro de la clasificación del instituto será propiamente usura (ilícita). Para estos autores, a diferencia de posturas más antiguas, no todo aumento o lucrum constituye un ilícito moral (y eventualmente jurídico) y por tanto, si usura significa todo aumento sobre el capital del mutuo, no toda usura será ilícita.

En relación a esta segunda postura el investigador discrepa y guarda distancia epistémica con el autor por cuanto todo aumento u lucrum injustificado sobre el capital representa un acto ilícito que abarca los aspectos financieros, económicos y jurídicos, por lo que, se configura a criterio del investigador el tipo penal de usura en detrimentos 
del patrimonio personal de las víctimas ocasionando un daño causado sumamente gravoso.

\section{DISCUSIÓN}

La usura se ha mantenido a lo largo de los tiempos a pesar de la intención de limitarla. La ley debe ser el medio idóneo para evitar este flagelo que atenta contra la seguridad patrimonial de las víctimas que ven socavada su estabilidad financiera y económica por la acción inescrupulosa y dolosa de los usureros, que muchas veces forman parte de una red criminal de delincuencia organizada.

La evolución histórica que ha tenido este delito en la legislación ecuatoriana, ha sido notable, al respecto se encuentra la ley contra la usura publicada en el registro oficial 108, que data del 18 de abril de 1967, la cual consideró tres aspectos importantes para el contexto de la época, referidos al crecimiento de la usura en el Ecuador, la impunidad generada ante la mala decisión de los jueces que fallaban en contra de las víctimas, por lo que, la sana crítica estaba trastocada. Es importante resaltar que dicho instrumento jurídico aún se encuentra vigente.

En este marco legal, el Consejo de la Judicatura emprendió una campaña contra los usureros por cuanto la comisión de este delito estaba vinculada a otros tipos penales graves tales como: Sicariato, Narcotráfico, Asesinato y Lavado de activos. Asimismo, era considerado un hecho delictivo de autor, es decir, la conducta punible estaba orientada en la forma de vida del usurero, más que el acto mismo.

Los prestamos usuarios constituían una forma habitual de obtener ingresos, pero esta coyuntura generaba indefensión y por lo tanto se adecuó a través del Código Orgánico Integral Penal que data del año 2014, el supuesto de hecho atribuible a este hecho criminal tal y como lo ha hecho la legislación comparada, siendo necesario tener en cuenta lo planteado por (Nájera-González, 2014), sobre la necesidad de anclar la criminología modera a una episteme para conocer en contexto real el fenómeno delictivo. 


\section{CONCLUSIONES}

Se concluye que la usura representa un tipo penal que atenta contra la capacidad económica y financiera de las víctimas al ocasionar una disminución de su capital como consecuencia de estipularse un interés mayor al previsto en la ley, atentando contra el sistema financiero en detrimento de la política monetaria nacional, socavando el principio del comercio justo.

Desde el diagnóstico actual sobre la evolución del delito de usura en la legislación ecuatoriana, se concluye que la legislación penal vigente se adapta a la dimensión real de este tipo penal en armonía al contexto internacional, llenando los vacíos legales que presentaba el código penal cuya última modificación data del año 2012 y que fue derogado en el año 2014, por cuanto, permitía interpretaciones erróneas a favor de los usureros, en virtud de la errada apreciación delas pruebas por parte de los juzgadores.

\section{FINANCIAMIENTO}

No monetario.

\section{AGRADECIMIENTO}

A la Universidad Regional Autónoma de Los Andes, Quevedo; por motivar el desarrollo de la Investigación.

\section{REFERENCIAS CONSULTADAS}

Asamblea Nacional de la República del Ecuador. (2014). Código Orgánico Integral Penal [Comprehensive Organic Criminal Code]. Recuperado de https://n9.cl/g6sc

Asamblea Nacional Constituyente de la República del Ecuador, (2008). Constitución de la República del Ecuador. Montecristi. Registro Oficial 449 de 20-oct-2008. Recuperado de https://n9.cl/sia

Barroso-González, J. (2015). Los delitos económicos desde una perspective criminológica [Economic crime from a criminological perspective]. Revista IUS, 9(35), 95-122. 
Cesar Gabino Cando Vinces, Julio César De Jesús Arrias Añez, Cesar Paucar Paucar

Lértora-Mendoza, C. (2013). La usura en documentos académicos jurídicos novohispanos. [Usury in legal academic papers novohispanos]. IUShistoria, 6; 49-62.

Lopera-Echavarría, J, \& Ramírez-Gómez, C, \& Zuluaga-Aristazábal, M, \& OrtizVanegas, J. (2010). El método analítico como método natural. Nómadas. Critical Journal of Social and Juridical Sciences, 25(1).

Masabanda-Analuiza, G., Aman-Llerena, A., Montero-Solano, J., \& MasabandaAnaluiza, J. (2019). La evolución del derecho laboral de la mujer. Protección y fomento de la igualdad. [The evolution of women's labor law. Protection and promotion of equality]. IUSTITIA SOCIALIS, 4(7), 64-96. http://dx.doi.org/10.35381/racji.v4i7.355

Nájera-González, X. (2014). Criminología, derecho penal y uso de monitores electrónicos. Puntos de encuentro epistemológico en la protección de los derechos humanos y la seguridad pública. [Criminology, criminal law and the use of electronic monitors. Points of epistemological convergence in the protection of human rights and public security]. Revista IUS, 8(34), 101-124.

Ochoa-González, C, Sánchez-Villacres, A, \& Benítez-Astudillo, J. (2016). Incidencia del crédito informal en el crecimiento económico de los microempresarios en el cantón La Troncal, Ecuador. [Incidence of informal credit on the economic growth of microentrepreneurs in La Troncal canton, Ecuador]. Universidad, Ciencia y Tecnología, 20(80), 114-123.

Solórzano-Aveiga, K. (2018). La economía informal en zonas de influencia con financiamiento micro empresarial: caso de estudio, El Carmen, Ecuador. [The informal economy in areas of influence with micro business financing: Case study, El Carmen, Ecuador]. Revista Universidad y Sociedad, 10(5), 243-247.

Toral-Aguilar, A. (2015). El delito de Usura en la legislación ecuatoriana y su evolución del Código Penal al COIP. [The crime of Usury in Ecuadorian legislation and its evolution from the Penal Code to the COIP]. Trabajo de titulación. Universidad del Azuay - Ecuador. Recuperado de https://n9.cl/qlrt 